\title{
Franz Xaver Winterhalter
}

\section{Das Sissi-Syndrom}

\author{
Viele Maler des 19. Jahrhunderts kommen uns heute \\ etwas angestaubt vor. Nicht wenige, die damals Be- \\ rühmtheiten waren, sind inzwischen vergessen. Das \\ gilt auch für Franz Xaver Winterhalter. Selbst Kenner \\ der Kunstgeschichte fragen bei dem Namen gerne \\ noch einmal nach: Franz Xaver Wer? Ein Werk von \\ ihm aber hat es dennoch geschafft zu überdauern \\ und fasziniert heute wie damals: sein Porträt der \\ Kaiserin Elisabeth von Österreich. Nie wurde "Sissi" \\ schöner dargestellt als von ihm.
}

n der ersten Hälfte des 19. Jahrhunderts wurde Franz Xaver Winterhalter durchaus zu den ganz Großen seines Fachs gezählt. Er schuf als gefragter Maler des europäischen Hochadels mehr als nur Porträts - er fabrizierte Wunschbilder. Nicht realistische Wiedergabe oder gar psychologische Durchdringung stand auf seinem Programm, sondern die Stilisierung und Überhöhung der Dargestellten. Das Portät als Form der Selbstdarstellung und Mittel zur Öffentlichkeitsarbeit - das kam bei seinen prominenten Auftraggebern gut an. Und bei Österreichs Kaiserin ist es ihm ganz besonders gut gelungen. Wie die endlose Haarpracht noch betont wird durch die eingeflochtenen Sternendiademe und sich unterhalb der schlanken Taille das Kleid zu einer einzigen Tüllkaskade aufbauscht - das ist schon sehr effektsicher in Szene gesetzt.

Für die Nachgeboren des Medienzeitalters ist das Bild der österreichischen Herrscherin eher durch das Kino geprägt. Die „Sissi“-Filme der 50er-Jahre sind so sehr Teil des kollektiven Unterbewusstseins geworden, dass sich viele Besucher der Wiener Hofburg vor Winterhalters Porträt verwundert fragen, warum das denn so wenig Ähnlichkeit mit Romy Schneider hat. Dabei war das wahre Leben der Kaiserin bei Weitem nicht so märchenhaft wie es Winterhalters Prachtschinken und die kunterbunten Kinoschnulzen suggerieren. Als unkonventionelles bayerisches Mädel aus niederem Adel schon als 16-Jährige mit dem österreichischen Kaiser verheiratet, wurde Sissi am Wiener Hof nie wirklich heimisch. Vor der strengen Etikette und der allgegenwärtigen Schwiegermutter flüchtete sie sich bald in andere Welten. Ausgedehnte Reisen gehörten dazu, aber auch eine Leidenschaft, die bald zu Obsession wurde: der Erhalt ihrer Jugend und die Pflege ihrer Schönheit.

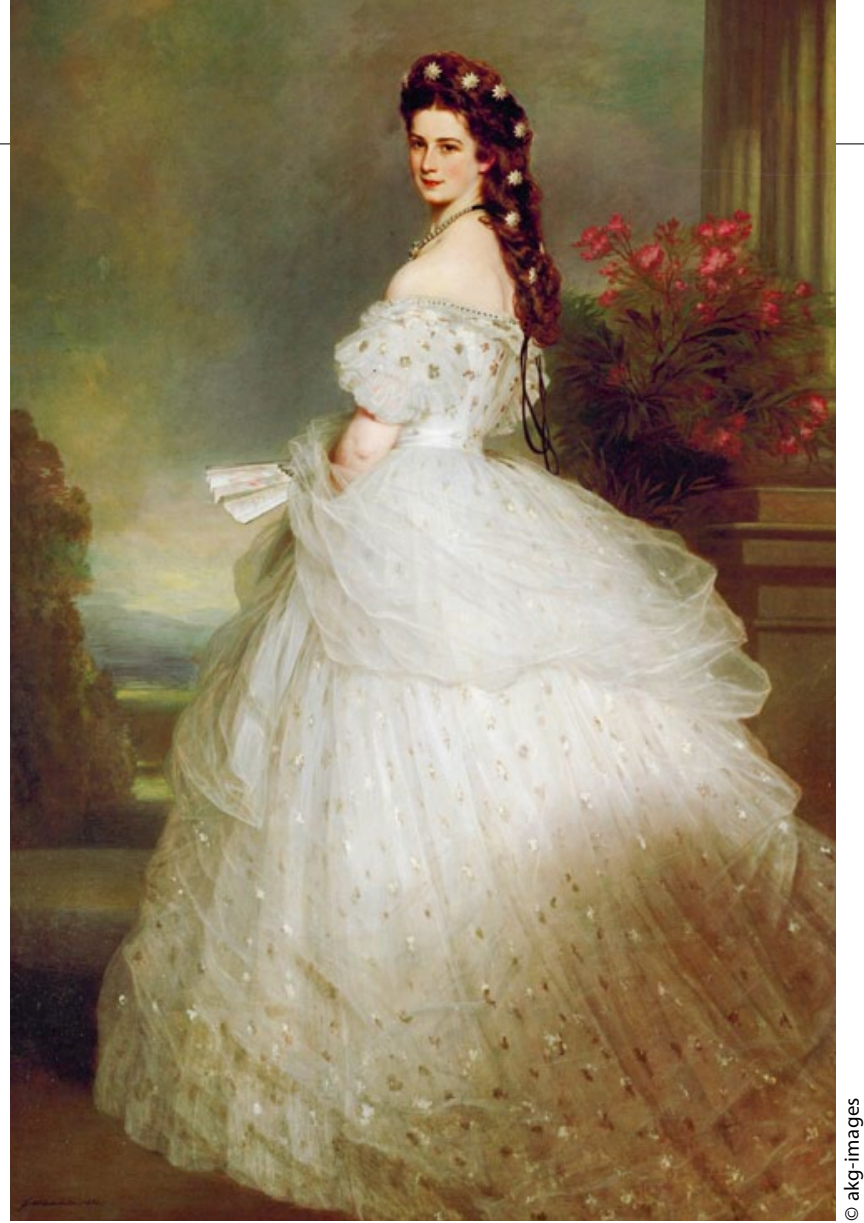

„Kaiserin Elisabeth von Österreich“, 1865, Franz Xaver Winterhalter (1805-1873)

In einer Zeit, in der Frauen über 30 häufig bereits als Matronen abgestempelt wurden, tat Sissi auch nach vier Geburten alles, um ihre schlanke Linie und die schmale Taille zu halten. Bei einer Körpergröße von $172 \mathrm{~cm}$ achtete sie strikt darauf, ein Gewicht von $50 \mathrm{~kg}$ nicht zu überschreiten. Wiederholte Fastenkuren dienten diesem Ziel ebenso wie ein tägliches Trainingsprogramm, das manchem Leistungssportler zur Ehre gereichen würde. Ihre heimischen Gemächer stattete sie mit - heute noch zu besichtigen - Turnringen und Trainingsgeräten für ihre regelmäßigen Gymnastikübungen aus. Legendär ist auch der Aufwand, den Sissi um ihre fast knöchellangen Haare trieb. Das tägliche Frisieren nahm mehrere Stunden in Anspruch. Das etwa alle drei Wochen durchgeführte Waschen dauerte beinahe einen ganzen Tag. Kein Wunder also, dass die Hüterin der herrscherlichen Haarpracht, die Friseurin Fanny Angerer, allmählich zur engsten Vertrauten Sissis wurde - und schließlich mehr verdiente als ein Universitätsprofessor.

Viele der damaligen Zeitgenossen schüttelten über derartige Exaltiertheiten den Kopf. Aus heutiger Sicht erscheint uns Kaiserin Elisabeth dagegen erstaunlich modern - und zwar gerade wegen ihrer zweifellos vorhandenen psychopathologischen Auffälligkeiten. Essstörungen sind längst zu einem Massenphänomen junger Mädchen geworden. Sport als Droge und Körperkult als Ersatzbefriedigung für ein ansonsten unerfülltes Leben sind es sicherlich nicht weniger. Und von der Vergötzung der Schönheit als scheinbar wichtigstem Merkmal des Menschen lebt inzwischen eine ganze Industrie. So müssen wir uns angesichts dessen heute wohl die Frage stellen: Sind wir nicht alle ein bisschen sissi?

Prof. Dr. med. Bernd Kleine-Gunk, Fürth 